\title{
Monocyte Traffic, Dorsal Root Ganglion Histopathology, and Loss of Intraepidermal Nerve Fiber Density in SIV Peripheral Neuropathy
}

Jessica R. Lakritz, ${ }^{*}$ Ayman Bodair, ${ }^{*}$ Neal Shah, ${ }^{*}$ Ryan $0^{\prime}$ Donnell, ${ }^{\dagger}$ Michael J. Polydefkis, ${ }^{\dagger}$ Andrew D. Miller, ${ }^{\ddagger}$ and Tricia H. Burdo*

From the Department of Biology, * Boston College, Chestnut Hill, Massachusetts; the Department of Neurology, ${ }^{\dagger}$ Johns Hopkins University School of Medicine, Baltimore, Maryland; and the Department of Biomedical Sciences, ${ }^{\ddagger}$ Section of Anatomic Pathology, Cornell University College of Veterinary Medicine, Ithaca, New York

Accepted for publication

March 3, 2015.

Address correspondence to Tricia H. Burdo, Ph.D.,

Department of Biology, Boston College, 140 Commonwealth Ave, Higgins Hall 445, Chestnut Hill, MA 02467. E-mail: burdot@bc.edu.

\begin{abstract}
HIV-associated sensory neuropathy remains the most common neurological complication of HIV infection and is characterized by dorsal root ganglion (DRG) inflammation and intraepidermal nerve fiber density (IENFD) loss. Chronic peripheral immune cell activation and accumulation may cause damage to the DRG, but has not been fully investigated yet. By using an SIV-infected, CD8-lymphocyte-depleted rhesus macaque model, we defined immune cells surrounding DRG neurons and their role in DRG pathology, measured cell traffic from the bone marrow to the DRGs using 5-bromo-2-deoxyuridine (BrdU) pulse, and serially measured IENFD. We found an increase in $\mathrm{CD}^{+} 8^{+}$and $\mathrm{CD} 163^{+}$macrophages in DRGs of SIV-infected animals. MAC387 ${ }^{+}$recently recruited monocytes/macrophages were increased, along with $\mathrm{BrdU}^{+}$cells, in the DRGs of SIV-infected macaques. We demonstrated that $78.1 \%$ of all BrdU ${ }^{+}$cells in DRGs were also $\mathrm{MAC}_{38} 7^{+}$. The number of $\mathrm{BrdU}^{+}$monocytes correlated with severe DRG histopathology, which included neuronophagia, neuronal loss, and Nageotte nodules. These data demonstrate that newly recruited $\mathrm{MAC}_{38} 7^{+} \mathrm{BrdU}^{+}$macrophages may play a significant role in DRG pathogenesis. IENFD decreased early (day 21), consistent with the development of sensory neuropathy in SIV-infected macaques. Decreased IENFD was associated with elevated BrdU ${ }^{+}$cells in the DRG. These data suggest that increased recruitment of macrophages to DRG is associated with severe DRG histopathology and IENFD loss. (Am J Pathol 2015, 185: 1912-1923; http://dx.doi.org/10.1016/j.ajpath.2015.03.007)
\end{abstract}

Peripheral neuropathy $(\mathrm{PN})$ is the most common neurological complication of HIV and continues to negatively affect patient quality of life. ${ }^{1,2}$ Distal sensory polyneuropathy (DSP) is a common type of HIV-PN that persists despite the decreased use of neurotoxic antiretroviral drugs. ${ }^{1-4}$ HIV-DSP is identical to antiretroviral toxic neuropathy clinically; both result in pain, numbness, and hypersensitivity in the lower legs and feet, as well as sometimes in the hands. ${ }^{1,5}$ Despite the clinical similarities, the underlying pathophysiological mechanisms of HIV-DSP and antiretroviral toxic neuropathy are unique.

HIV-DSP is sensory nerve fiber axonal degeneration in the extremities. ${ }^{5}$ It is unclear if this axonal degeneration is a result of HIV's direct damage to nerve fibers or indirect damage by activated macrophages and glial cells in the dorsal root ganglion (DRG). ${ }^{6}$ Histopathology of the DRG during HIV infection consists of an increased number of macrophages, decreased lymphocytes, fewer neurons, and increased Nageotte nodules.

The study of the pathology of PN in HIV-infected human subjects is confounded by the use of antiretroviral drugs, including nucleotide reverse transcriptase inhibitors and protease inhibitors, which may cause antiretroviral toxic neuropathy. HIV-PN pathology can be confounded by increased alcohol consumption ${ }^{7}$ and vitamin B12 deficiency. ${ }^{8}$ Diagnosis of PN in humans relies on a combination of autonomic testing results, nerve biopsy specimens, and skin biopsy specimens.

Supported by NIH/National Institute of Neurological Disorders and Stroke grant R01 NS082116 (T.H.B.), a Tulane National Primate Research Center (TNPRC) pilot grant (T.H.B.), and the TNPRC's base grant NIH P51 RR00164. The in vivo CD8 T-lymphocyte depletion antibodies were provided by the NIH Nonhuman Primate Reagent Resource (grants RR016001 and AI040101).

Disclosures: None declared. 
However, examining intraepidermal nerve fiber densities (IENFDs) via skin biopsy specimens is an objective pathological measure of PN pathogenesis.

Animal models lend themselves to the study of viral pathogenesis and immune response. ${ }^{10}$ Transgenic mice expressing gp120 have failed to develop PN after 2 months. ${ }^{11}$ However, in a murine immunodeficiency virus model ${ }^{12}$ and after perineural application of gp120 to the sciatic nerve in rats, ${ }^{13}$ peripheral nerve damage has been shown. Feline immunodeficiency virus recapitulates PN damage with HIV infection, but the virus uses a different coreceptor (CD134) ${ }^{14,15}$ SIV is particularly attractive given the similarities between humans and nonhuman primates, with SIV being closely related to HIV genomically, structurally, and clinically. ${ }^{10,16}$ Both viruses target the $\mathrm{CD} 4{ }^{+}$lymphocytes, monocytes, and macrophages through CD4 and CCR5, resulting in immune suppression and neuropathology that includes a decline in IENFDs and similar pathology in the DRG. ${ }^{10}$

By using a neurovirulent clone and immunosuppressive SIV swarm in pigtailed macaques, Mankowski and colleagues demonstrated that the $\mathrm{SIV}^{+}$cells in the DRG were $\mathrm{CD} 8^{+}$macrophages and that damage to the DRG precedes loss of nerve fibers in the skin. ${ }^{17-19}$ We have previously demonstrated that $\mathrm{CD}^{+}$lymphocyte-depleted, SIV-infected rhesus macaques rapidly develop AIDS and histopathology that reproduces the hallmarks of human HIV infection preantiretroviral therapy, including SIV encephalitis, lymph damage, the depletion of gut $\mathrm{T}$ cells, and $\mathrm{PN} .{ }^{20-22}$

Because HIV and SIV are unable to productively infect neurons, damage at the DRG is thought to be due to infected and activated macrophages and glial cells, which can secrete neurotoxic products. ${ }^{23}$ Whether inflammation or recruited monocytes/macrophages play a role in damage has yet to be defined in an experimental SIV model. Factors involved in immune cell trafficking to the DRG during HIV/SIV infection are poorly understood. Previous studies have used CD68 or ionized calcium binding adaptor protein 1 (Iba-1) as monocyte/macrophage markers in the DRG. ${ }^{17,20,24}$ However, these markers do not differentiate between circulating and infiltrating monocytes/macrophages and resident macrophages. It is likely that resident macrophages $\left(\mathrm{CD} 68^{+}\right.$ and $\mathrm{CD} 163^{+}$) and infiltrating macrophages $\left(\mathrm{MAC} 387^{+}\right.$) play different roles during HIV-associated DRG damage, ${ }^{25}$ as do M1 versus M2 cells at the DRG.

\section{Materials and Methods}

\section{Ethical Statement}

All animals used in this study were handled in strict accordance with American Association for Accreditation of Laboratory Animal Care, the Harvard University's (Cambridge, MA) Institutional Animal Care and Use Committee (protocol 04785), or Tulane University's (New Orleans, LA) Institutional Animal Care and Use Committee (protocols P0066 and P0263), and these committees approved all animal work. This work was also approved by Boston College's (Chestnut

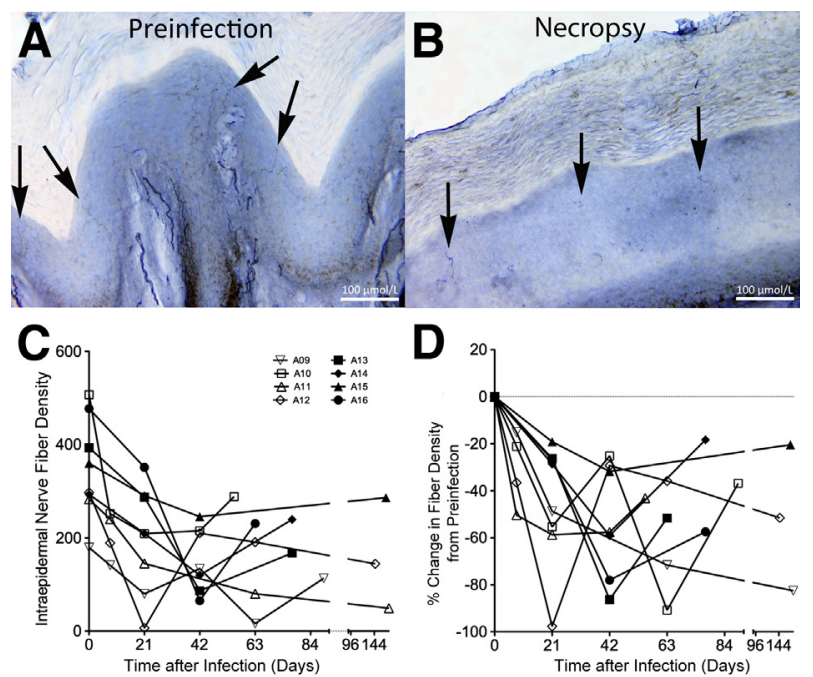

Figure 1 Intraepidermal nerve fiber density (IENFD) decreases after infection. A: Preinfection biopsy of animal A11 has several long contiguous IENFs terminating in the basement layer of the stratum corneum (arrows). B: Biopsy specimen of animal A11 taken at necropsy on AIDS has few segmented IENFs (arrows). C: IENFD was serially measured, and the IENFD per animal at each time point is graphed. D: The percentage change in IENFD at the individual times from preinfection was calculated using the animal's own preinfection value as a reference. Open symbols indicate cohort of SIVinfected animals (A09 to A12) in which biopsy specimens were taken at days $0,8,21,42$, and 63 after infection and necropsy; closed symbols, cohort of SIV-infected animals (A13 to A16) in which biopsy specimens were taken at days $0,21,42$, and 63 after infection and necropsy.

Hill, MA) Institutional Animal Care and Use Committee (protocol 2013-002). All possible measures are taken to minimize discomfort of the animals. All procedures were performed using chemical restraint to ensure the safety of both staff and animals, and the choice of anesthetic included 10 to $20 \mathrm{mg} / \mathrm{kg}$ ketamine, 4 to $10 \mathrm{mg} / \mathrm{kg}$ telazol, and/or 7.5 to $15 \mu \mathrm{g} / \mathrm{kg}$ dexdomitor (all i.m.), depending on the procedure.

\section{Animals, Viral Infection, and CD8 Lymphocyte Depletion}

Sixteen rhesus macaques (Macaca mulatta) were used in this study. Animals were randomly assigned to experimental groups. Four uninfected control animals were used in this study, two of which were CD8 lymphocyte depleted by treatment with mouse-rhesus chimeric anti-CD8a antibody cM-T807 administered only once at $50 \mathrm{mg} / \mathrm{kg}$ i.v. Twelve animals were inoculated i.v. with SIVmac251 (a generous gift from Dr. Ronald Desrosiers, University of Miami, Coral Gables, FL). Infected animals were administered $10 \mathrm{mg} / \mathrm{kg}$ of anti-CD8 antibody s.c. at day 6 after infection, and $5 \mathrm{mg} /$ $\mathrm{kg}$ i.v. at days 8 and 12 after infection, to achieve rapid AIDS with a high incidence of SIV encephalitis (SIVinfected CD8 lymphocyte depleted). The human anti-CD8 antibody was provided by the NIH Non-Human Primate Reagent Resource (grants RR016001 and AI040101). ${ }^{26-31}$

All animals were anesthetized with ketamine-hydrochloride, euthanized by an i.v. pentobarbital overdose, and exsanguinated. 
Table 1 Animals Used in the Study

\begin{tabular}{lllllll}
\hline \multirow{2}{*}{ Animal groups } & Animal & Primate & Survival, \\
no. & center & Tays & $\begin{array}{l}\text { Terminal plasma } \\
\text { viral load, log 10 }\end{array}$ & $\begin{array}{l}\text { Brain } \\
\text { pathology }\end{array}$ \\
\hline Uninfected & A01 & NEPRC & NA & NA & Normal & Normal \\
& A02 & NEPRC & NA & NA & Normal & Normal \\
& A03 & TNPRC & NA & NA & Normal & Normal \\
SIV-infected CD8 & A04 & TNPRC & NA & NA & Normal & Normal \\
lymphocyte depleted & A05 & NEPRC & 77 & 8.69 & SIVE & Severe \\
& A06 & NEPRC & 131 & 8.15 & SIVE & Mod-severe \\
& A07 & TNPRC & 91 & 7.04 & SIVE & Mod-severe \\
& A08 & NEPRC & 56 & 7.86 & SIVE & Moderate \\
& A09 & TNPRC & 89 & 7.71 & SIVE & Mild (T), mod-severe (L, S) \\
& A10 & TNPRC & 55 & 7.83 & SIVE & Mild (T), mild-mod (L, S) \\
& A11 & TNPRC & 174 & 7.28 & AIDS no E & Severe (T, L, S) \\
& A12 & TNPRC & 146 & 7.67 & AIDS no E & Moderate (T), severe (L, S) \\
& A13 & NEPRC & 77 & 8.54 & SIVE & Moderate (T), mod-severe (L, S) \\
& A14 & NEPRC & 77 & 7.23 & SIVE & Moderate (T, L, S) \\
& A15 & NEPRC & 168 & 6.79 & AIDS no E & Mild (L, S) \\
& A16 & NEPRC & 97 & 7.79 & SIVE & Mild (L, S) \\
\hline
\end{tabular}

*Sections of DRGs from animals A01 through A08 contained multiple DRGs per block, but specific anatomical location was not specified so they may have included thoracic, lumbar, and/or sacral DRGs.

AIDS no E, AIDS without SIVE; DRG, dorsal root ganglion; L, lumbar DRG; mod, moderate pathology; NA, not applicable; NEPRC, New England Primate Research Center; S, sacral DRG; SIVE, SIV encephalitis; T, thoracic DRG; TNPRC, Tulane National Primate Research Center.

Animals were sacrificed on the basis of the following guidelines for euthanasia of SIV-infected rhesus macaques: i) weight loss $>15 \%$ in 2 weeks, $30 \%$ body weight in 2 months, or $25 \%$ overall, ii) documented opportunistic infection, iii) persistent anorexia $>3$ to 5 days without explicable cause, iv) severe intractable diarrhea (ie, nonresponsive to standard treatment and results in dehydration and debilitation of the animal), v) progressive neurological signs (ie, instability on the perch bar, depression, head tilt, nystagmus, ataxia, stupor, or depression), vi) significant cardiac and/or pulmonary signs (ie, dyspnea, open-mouthed breathing, or severe, previously unrecognized, cardiac murmur, especially if resulting in pulmonary edema), vii) persistent leukopenia, viii) progressive or persistent anemia, ix) signs of progressive immunosuppressive disease, $x$ ) body condition score $>1.5 / 5$ with weight loss, or xi) any other serious illness.

All SIV-infected animals developed simian AIDS-defining lesions, as determined postmortem by the presence of the following: Pneumocystis carinii-associated interstitial pneumonia, Mycobacterium avium-associated granulomatous enteritis, hepatitis, lymphadenitis, and/or adenovirus infection of surface enterocytes in both small and large intestines. Animals were housed at either the New England Primate Research Center (Southborough, MA) or Tulane University's National Primate Research Center (Covington, LA), in strict accordance with standards of the American Association for Accreditation of Laboratory Animal Care.

\section{BrdU Administration}

A $30 \mathrm{mg} / \mathrm{mL}$ stock of solution was prepared by adding 5-bromo-2-deoxyuridine (BrdU; Sigma-Aldrich, St. Louis, MO) to $1 \times$ phosphate-buffered saline (without $\mathrm{Ca}^{2+}$ and
$\mathrm{Mg}^{2+}$ ) and heated to $60^{\circ} \mathrm{C}$ in a water bath, as previously described. ${ }^{21} \mathrm{BrdU}$ was administered as a slow bolus i.v. injection at a dose of $60 \mathrm{mg} \mathrm{BrdU} / \mathrm{kg}$ body weight. BrdU was administered at days $8,21,42$, and 62 , and 24 hours before necropsy in animals A05 to A12 and days 42 and 62, and 24 hours before necropsy in animals A13 to A16.

\section{Necropsy and Histopathology}

Animals underwent necropsy immediately after death, and representative sections of all major organs were collected, fixed in 10\% neutral-buffered formalin, embedded in paraffin, divided into sections ( $5 \mu \mathrm{m}$ thick), and stained using hematoxylin and eosin. After deparaffinization in xylene, the tissues were hydrated in graded alcohols, counterstained with Harris Hematoxylin Solution (Sigma-Aldrich) for 2 minutes, and rinsed with running water. The slides were then dipped sequentially in acid alcohol (90\% methanol, 5\% sulfuric acid, and 5\% acetic acid; Sigma-Aldrich) and ammonia water $(750 \mu \mathrm{L}$ ammonium hydroxide in $250 \mathrm{~mL}$ water; SigmaAldrich), rinsing with running water after each, followed by $80 \%$ alcohol for 2 minutes, and eosin (Sigma-Aldrich) for 2 minutes. Tissue sections were then rinsed in graded alcohols, dehydrated with xylene, and mounted with VectaMount (Vector Labs, Burlingame, CA).

\section{Histopathological Analysis of DRG Morphology}

Hematoxylin and eosin-stained sections of DRG were evaluated blindly for histopathological lesions by a boardcertified veterinary anatomical pathologist (A.D.M.) and scored on the basis of the presence and severity of infiltrating 


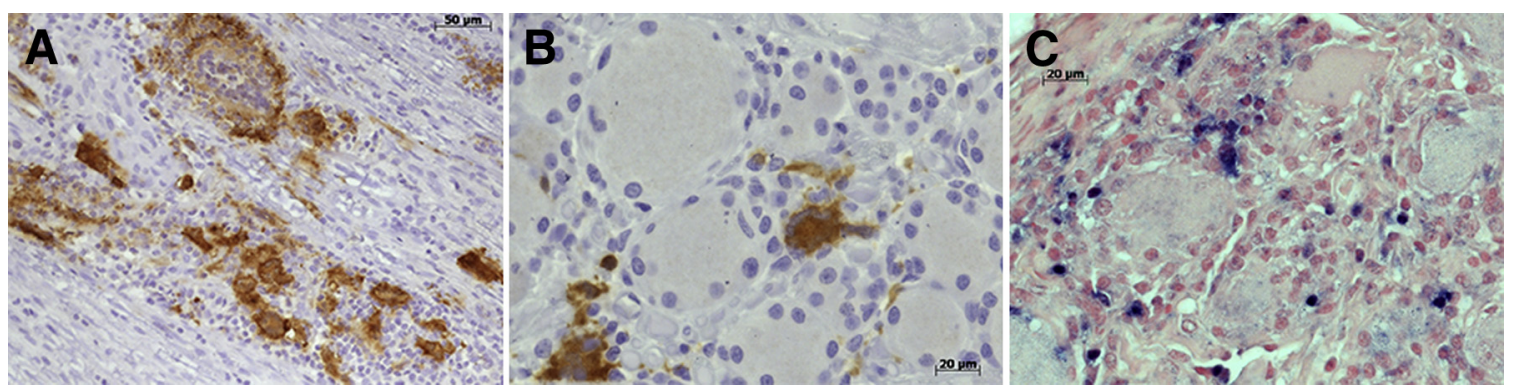

Figure 2 Productive viral replication in the macrophage in the dorsal nerve root and dorsal root ganglion (DRG) of SIV-infected macaques. A: Dorsal nerve root of animal A11 with abundant SIVp28 (brown) immunoreactivity and multinucleated giant cells (MNGCs) in SIV-infected rhesus macaque. B: DRG of animal A06 with abundant SIVp28 (brown) immunoreactivity and a MNGC. C: DRG of animal A05 with in situ hybridization identifying SIV RNA ${ }^{+}$cells (blue).

mononuclear cells, neuronophagia, and neuronal loss/ degeneration, as previously described..$^{20}$ Ganglionitis was scored via the following criteria: i) mild to mild-moderate (mild), scattered infiltrating mononuclear cells with rare evidence of neuronophagia and/or neuronal loss (grade of 1 or 1.5 ); ii) moderate to moderate-severe (moderate), increased numbers of infiltrating mononuclear cells with occasional neuronophagia and/or neuronal loss (grade of 2 or 2.5); and iii) severe (severe), abundant infiltrating mononuclear cells, frequent neuronophagia, and neuronal loss were all present (grade of 3). ${ }^{18,20}$

\section{Immunohistochemistry}

DRG sections were deparaffinized with xylene, hydrated in a series of graded alcohols, and stained with anti-SIV protein p28 (Fitzgerald, Acton, MA), the pan-macrophage marker anti-CD68 (clone KP1; Dako, Carpinteria, CA), the scavenger receptor anti-CD163 (clone MCA1853; Serotec, Raleigh, NC), the early inflammatory marker anti-MAC387 (clone M0747; Dako), anti-BrdU (clone M0744; Dako), or the T-lymphocyte marker anti-CD3 (clone A0452; Dako). Sections were counterstained with hematoxylin, dehydrated, mounted using VectaMount permanent mounting medium (Vector Labs), visualized, and imaged using a Zeiss Axio Imager M1 microscope (Carl Zeiss MicroImaging, Inc., Thornwood, NY) using Plan-Apochromat $\times 20 / 0.8$ and $\times 40$ / 0.95 Korr objectives.

\section{Quantitation of Monocytes/Macrophages in DRGs}

For quantitation of monocyte/macrophage populations by immunohistochemical analyses, eight nonoverlapping fields at $\times 200$ magnification were quantitated per DRG tissue. Data were expressed as means \pm SEM. The percentage of immunepositive cells was calculated as follows: number of positively stained cells (diaminobenzidene-positive brown cells)/the total number of satellite cells [total hematoxylin (blue nuclei)-positive cells] surrounding the DRGs, multiplied by 100 . The absolute number of cells was calculated by dividing the number of positively stained cells (diaminobenzidenepositive brown cells) by the area of tissue examined (cells/ $\mathrm{mm}^{2}$ ). Each nonoverlapping field at $\times 200$ magnification was $0.147 \mathrm{~mm}^{2}$.

\section{Immunofluorescence}

Dual-immunofluorescence staining was performed on paraffinized DRG tissue sections, as previously described. ${ }^{25}$ DRG slides were stained with anti-BrdU (clone M0744; Dako), anti-MAC387 (clone MCA874G; Serotec, Raleigh, NC), or anti-CD68 (clone KP1; Thermo Fisher Scientific, Waltham, MA). MAC387 and CD68 antibodies were biotinylated with DSB-X Biotin Protein Labeling Kit (Life Technologies, Carlsbad, CA), according to the manufacturer's instructions. Endogenous biotin was blocked using Avidin/Biotin Blocking Kit (Vector Labs), according to the manufacturer's instructions. The secondary antibodies used were goat antimouse IgG1-AlexaFluor488 (Molecular Probes, Eugene, OR) and Streptavidin-AlexaFluor568 (Molecular Probes), both at a 1:500 dilution. After immunofluorescence labeling, tissue sections were treated with $50 \mathrm{mmol} / \mathrm{L} \quad \mathrm{Cu}_{3} \mathrm{SO}_{4}$ ammonium buffer for 45 minutes at room temperature to quench autofluorescence. Single-color controls and doublenegative control slides were used to determine potential spectral overlap of fluorophores. Slides were mounted with Vectashield mounting media containing DAPI (Vector Labs) and visualized under a microscope (Zeiss Axio Imager.M1; Carl Zeiss Microimaging, Thornwood, NY). Blue, red, and green color channels were collected simultaneously and analyzed using computer software (AxioVision version 4.6.3; Carl Zeiss, Thornwood, NY).

\section{Quantitation of Double-Labeled $\mathrm{BrdU}^{+} \mathrm{MAC} 87^{+}$and $\mathrm{BrdU}^{+} \mathrm{CD} 68^{+}$Cells}

For quantitation of double-labeled $\mathrm{BrdU}^{+} \mathrm{MAC} 387^{+}$or $\mathrm{BrdU}^{+} \mathrm{CD}^{+} 8^{+}$cells, 8 to 11 nonoverlapping fields at $\times 200$ magnification were examined per DRG tissue. Alexa568 ${ }^{+}$ or Alexa $488^{+}$cells only and overlapping Alexa568 ${ }^{+}$and Alexa $488^{+}$cells were quantified. The percentage of doublepositive cells was calculated by dividing the number of double-positive cells by the number of total positive cells (total of single and double positive), multiplied by 100. Data 
Table 2 Percentage of Cell Populations Surrounding DRG Neurons and Absolute Number of Inflammatory Cells in DRGs

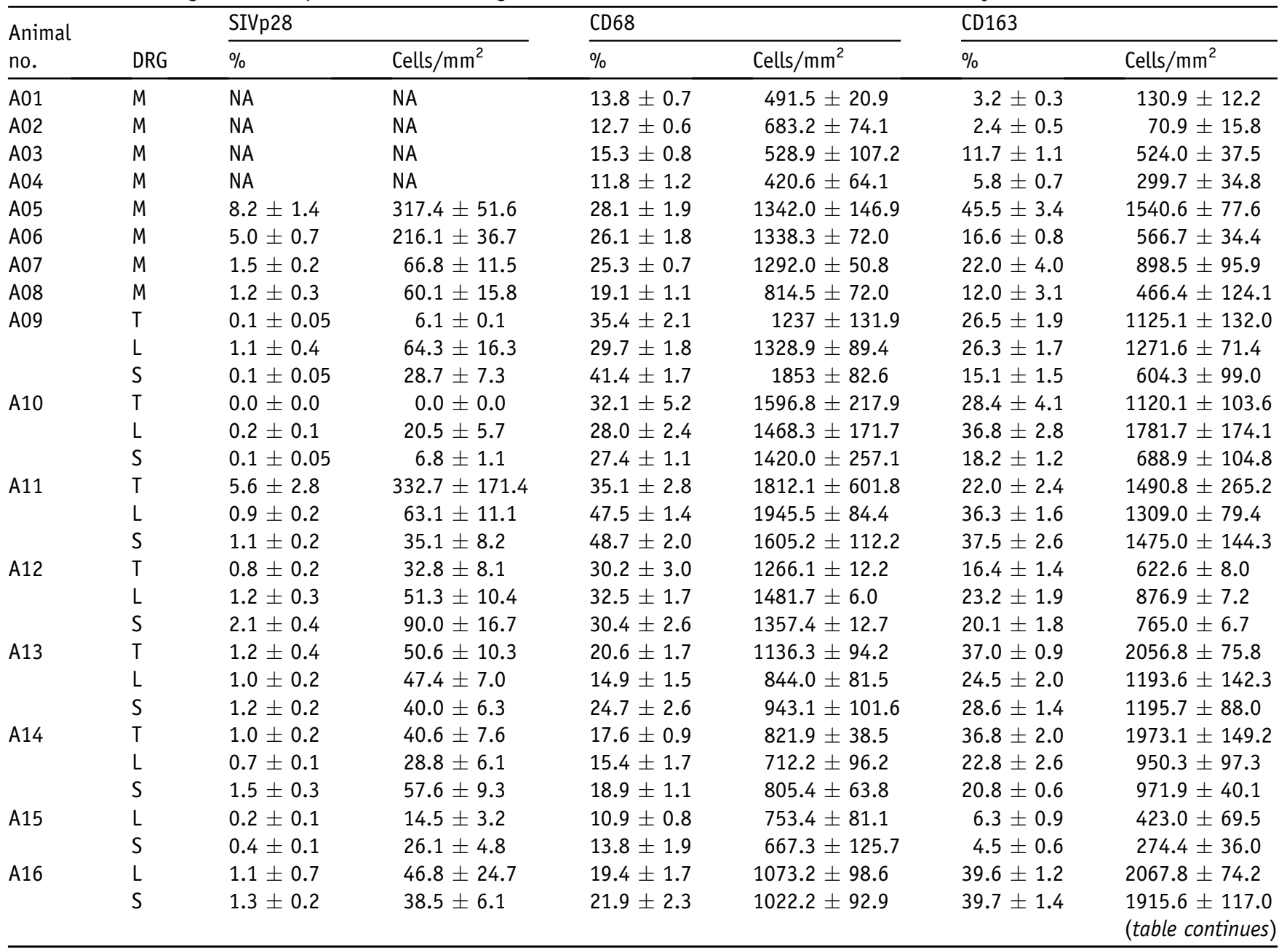

Means \pm SEM are shown. The percentage of positive cells was calculated as the number of positively stained cells divided by total satellite cells (total hematoxylin-positive cells) surrounding the DRGs, multiplied by 100 . Eight $\times 20$ fields were used for each measurement. The absolute number of cells was calculated as the cells $/ \mathrm{mm}^{2}$ in eight separate $0.147-\mathrm{mm}^{2}$ fields by dividing the number of positive cells in the field by the size of the field examined (for a $\times 20$ field, it was $0.147 \mathrm{~mm}^{2}$ ).

DRG, dorsal root ganglion; L, lumbar DRG; M, multiple DRGs per block, specific anatomical location was not specified, may include thoracic, lumbar, and/or sacral DRG; NA, not applicable; S, sacral DRG; T, thoracic DRG.

were expressed as means \pm SEM. The averages shown are weighted averages and the SEM (pooled variance).

\section{In Situ Hybridization}

In situ hybridization for SIV RNA was performed using digoxigenin-labeled antisense riboprobes (Lofstrand Labs, Gaithersburg, MD), as previously described. ${ }^{32-34}$ The probes were synthesized from five DNA templates that spanned $90 \%$ of the SIV genome.

\section{Skin Punch and IENFD Measurement}

Skin punch biopsy specimens with IENF were performed in 8 of the 12 SIV-infected animals (A09 to A16). Skin punches $(3 \mathrm{~mm})$ were taken serially near the sural innervation site just distal to the lateral malleolus. Biopsy specimens were taken for each animal at preinfection and every 2 weeks starting at 8 days after infection to necropsy, 24 hours after BrdU injection. Biopsy specimens were fixed in Zambonis fixative and processed for dividing into sections. Sections $(50 \mu \mathrm{m}$ thick) of serial punch skin biopsy specimens were stained with anti-PGP 9.5, a panaxonal marker (1:10,000 dilution; ABD Serotec, Oxford, UK).

Intraepidermal nerve fibers are conventionally counted by manual inspection and expressed as the number of fibers per linear length of epidermis (fibers/mm). Because the epidermis can be densely innervated in macaque skin compared with human, manual counting is difficult. ${ }^{17,35,36}$ To address this, the samples in this study were quantified using an unbiased stereology protocol that has been developed at the Johns Hopkins (Baltimore, MD) Cutaneous Nerve Laboratory. ${ }^{17,35,36}$ This approach requires that a technician define the boundaries of the structure that is counted. In this case, the boundaries are the 
Table 2 (continued)

\begin{tabular}{|c|c|c|c|c|c|}
\hline \multicolumn{2}{|l|}{ MAC387 } & \multicolumn{2}{|l|}{ BrdU } & \multicolumn{2}{|l|}{ CD3 } \\
\hline$\%$ & Cells $/ \mathrm{mm}^{2}$ & $\%$ & Cells $/ \mathrm{mm}^{2}$ & $\%$ & Cell $/ \mathrm{mm}^{2}$ \\
\hline $1.1 \pm 0.2$ & $45.2 \pm 10.3$ & $0.8 \pm 0.1$ & $40.5 \pm 4.4$ & $2.6 \pm 0.7$ & $101.1 \pm 24.0$ \\
\hline $0.7 \pm 0.1$ & $24.2 \pm 3.6$ & NA & NA & $7.0 \pm 0.5$ & $293.5 \pm 26.6$ \\
\hline $3.1 \pm 0.3$ & $146.6 \pm 19.6$ & NA & NA & $8.2 \pm 0.8$ & $345.4 \pm 27.8$ \\
\hline $11.1 \pm 0.9$ & $545.9 \pm 44.3$ & $4.7 \pm 0.7$ & $207.5 \pm 28.3$ & $7.6 \pm 1.4$ & $252.6 \pm 36.0$ \\
\hline $3.5 \pm 0.5$ & $136.2 \pm 17.6$ & $1.4 \pm 0.2$ & $54.0 \pm 7.8$ & $1.7 \pm 0.5$ & $96.3 \pm 23.3$ \\
\hline $2.6 \pm 0.5$ & $129.6 \pm 30.7$ & $2.4 \pm 0.3$ & $102.5 \pm 10.2$ & $6.0 \pm 3.0$ & $221.3 \pm 116.4$ \\
\hline $5.3 \pm 076$ & $229.1 \pm 33.0$ & $2.6 \pm 0.5$ & $124.6 \pm 22.8$ & $6.0 \pm 0.9$ & $284.3 \pm 46.5$ \\
\hline $3.9 \pm 0.5$ & $152.0 \pm 21.4$ & $2.2 \pm 0.5$ & $100.6 \pm 19.8$ & $7.0 \pm 1.1$ & $263.2 \pm 40.4$ \\
\hline $3.4 \pm 0.9$ & $131.4 \pm 30.6$ & $2.4 \pm 0.7$ & $79.0 \pm 20.4$ & $4.0 \pm 1.1$ & $143.9 \pm 51.9$ \\
\hline $4.3 \pm 0.4$ & $148.2 \pm 10.7$ & $2.9 \pm 0.6$ & $90.1 \pm 20.1$ & $9.0 \pm 1.1$ & $345.9 \pm 42.5$ \\
\hline $5.3 \pm 1.0$ & $183.0 \pm 7.1$ & $3.8 \pm 2.7$ & $165.0 \pm 12.7$ & $14.3 \pm 1.9$ & $476.8 \pm 6.3$ \\
\hline $9.1 \pm 2.2$ & $337.6 \pm 18.0$ & $9.0 \pm 1.5$ & $311.0 \pm 9.5$ & $14.8 \pm 1.5$ & $507.2 \pm 5.9$ \\
\hline $4.3 \pm 0.7$ & $179.7 \pm 4.8$ & $5.1 \pm 0.6$ & $228.4 \pm 4.7$ & $11.1 \pm 2.4$ & $405.0 \pm 8.0$ \\
\hline $3.6 \pm 0.7$ & $182.7 \pm 33.3$ & $1.7 \pm 0.3$ & $97.8 \pm 17.6$ & $1.9 \pm 0.4$ & $91.1 \pm 14.1$ \\
\hline $2.3 \pm 0.3$ & $144.1 \pm 12.0$ & $1.9 \pm 0.2$ & $96.5 \pm 8.9$ & $1.7 \pm 0.3$ & $88.8 \pm 13.3$ \\
\hline $2.0 \pm 0.3$ & $79.3 \pm 12.1$ & $2.9 \pm 0.3$ & $116.8 \pm 11.9$ & $2.4 \pm 0.3$ & $96.7 \pm 13.2$ \\
\hline $5.6 \pm 1.5$ & $286.1 \pm 78.5$ & $1.7 \pm 0.2$ & $91.8 \pm 9.2$ & $4.2 \pm 0.7$ & $217.2 \pm 34.8$ \\
\hline $3.3 \pm 0.5$ & $136.1 \pm 18.7$ & $2.0 \pm 0.3$ & $95.8 \pm 15.6$ & $3.5 \pm 0.4$ & $152.2 \pm 16.4$ \\
\hline $3.3 \pm 0.5$ & $126.6 \pm 17.6$ & $1.7 \pm 0.2$ & $84.5 \pm 13.7$ & $3.8 \pm 0.6$ & $174.3 \pm 30.0$ \\
\hline $2.5 \pm 0.2$ & $156.7 \pm 14.5$ & $1.3 \pm 0.2$ & $95.6 \pm 16.8$ & $1.2 \pm 0.3$ & $87.4 \pm 24.3$ \\
\hline
\end{tabular}

skin surface and the dermal/epidermal junction. A spherical probe of different sizes is then delivered at random by the stereo-investigator program (Space balls program; Microbrightfield Bioscience, Williston, VT) within this threedimensional region, and a technician determines whether the probe intersects with a nerve fiber. After several hundred samplings, the program delivers a measure of nerve fiber length/volume epidermis (IENFD). This approach is statistically valid $^{37}$ and provides an objective, unbiased approach to measuring the complex structures. The same approach has been used to quantify axons within the central nervous system.

\section{Statistical Analysis}

Prism software version 5.0f (GraphPad Software, Inc., San Diego, CA) was used for statistical analyses. Student's $t$-tests were used to detect variation cell number between uninfected and infected rhesus macaques. Analysis of variance was used to measure variation among cell populations in animals with different degrees of DRG pathology. $P<0.05$ was considered significant. If the analysis of variance was significant, then post hoc $t$-tests were performed. Nonparametric Spearman correlation was used, where $P<0.05$ was considered significant.

\section{Results}

\section{IENF Decrease with SIV Infection}

Serial skin biopsy specimens of the central footpad were obtained in 8 of the 12 SIV-infected rhesus macaques used in this study at preinfection and days 8, 21, 42, 63, and necropsy, and IENFDs were evaluated. The preinfection biopsy specimens had several long contiguous fibers terminating in 
the basement layer of the stratum corneum (Figure 1A), whereas the biopsy specimens taken at necropsy had few segmented fibers (Figure 1B). There was a decreased IENFD after SIV infection in all animals (Figure 1C). These data were standardized, where the percentage change in fiber density from preinfection was compared between the animals over time (Figure 1D). IENFD loss appeared to occur early in infection (by 8 to 21 days after infection), with an average loss of $45.2 \%$ (SEM, 7.4\%) with AIDS (range, $18.4 \%$ to 82.5\%) (Figure 1D).

\section{DRG Pathology}

All 12 SIV-infected CD8-depleted animals had some degree of DRG pathology (mild to severe). In 8 of the 12 animals, multiple levels of DRGs were examined, including DRGs from the thoracic, lumbar, and sacral regions. DRGs from mixed unspecified regions were examined in the remaining four infected animals. In these animals, we consistently detected more severe pathology in the lumbar and sacral DRGs compared with thoracic DRGs (Table 1). DRGs from all four uninfected animals had normal histology. There was a trend for animals that had severe DRG pathology in their lumbar and sacral DRGs to have greater loss of IENFD (data not shown). These data point to a potential association between IENFD loss and severe DRG pathology.

\section{Active Viral Replication in DRG Satellite Cells}

Viral infection in macrophages in the dorsal nerve root (Figure 2A) and the DRG (Figure 2, B and C) was seen in SIV-infected, CD8-depleted macaques. Multinucleated giant cells were seen in DRGs of two CD8-depleted, SIV-infected animals. The percentage and absolute number of SIV virally infected cells in the DRG ranged from 0 to 317 infected cells/ $\mathrm{mm}^{2}$, and $0 \%$ to $8.2 \%$ of the total cells surrounding the DRG neurons were productively infected (Table 2). Even in DRGs with low levels of productive viral infection, there was still notable pathology, including infiltrating mononuclear cells, neuronophagia, and neuronal loss. Therefore, active viral infection is not necessary for DRG damage and loss of neurons. Plasma viral load from all animals peaked early and remained elevated through the study. There was no significant difference between plasma viral loads between animals (data not shown).

\section{Resident Cell Activation in the DRG with SIV Infection}

Consistent with data previously reported, ${ }^{20}$ the percentage and absolute number of $\mathrm{CD}^{+} 8^{+}$cells surrounding DRG neurons were significantly increased in SIV-infected animals compared with uninfected controls $[P<0.01$ : mean, $13.3 \%$ (SEM, $0.8 \%$ ) versus $26.7 \%$ (SEM, 1.9\%); and $P<0.001$ : mean, 531.1 (SEM, 55.5) versus 1228.0 (SEM, 72.0) cells $/ \mathrm{mm}^{2}$, respectively] (Figure 3, A-C). DRGs were then divided into groups on the basis of the severity of
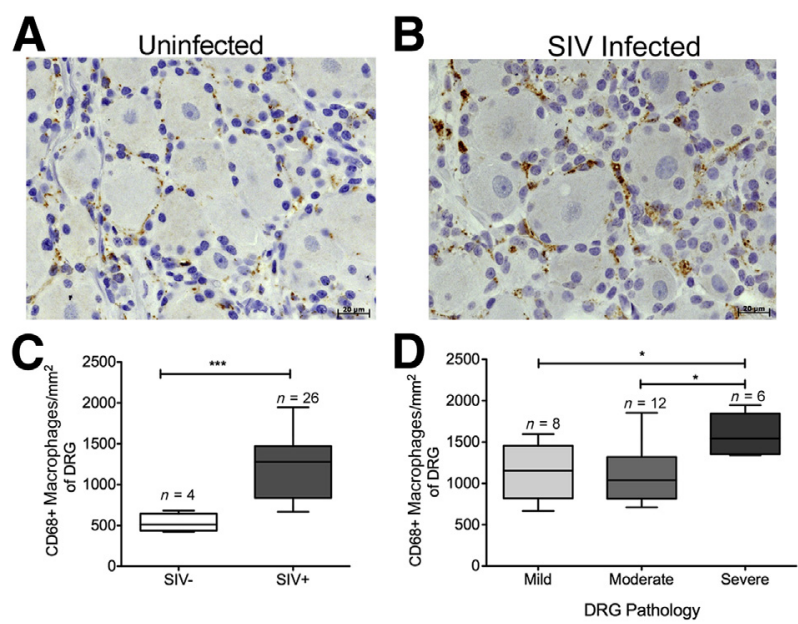

Figure 3 Elevated numbers of $\mathrm{CD} 68^{+}$macrophages are associated with SIV infection and severity of dorsal root ganglion (DRG) pathology. A: DRG of uninfected animal $A 01$ with scant CD68 immunoreactivity (brown). B: DRG of animal A08, a SIV-infected rhesus macaque with marked increase in CD68 immunoreactivity (brown). C: The box plot shows the absolute number of $\mathrm{CD}^{+} 8^{+}$cells per $\mathrm{mm}^{2}$ in $\mathrm{SIV}^{-}$and $\mathrm{SIV}^{+}$DRGs. The absolute number of $\mathrm{CD} 68^{+}$ cells per $\mathrm{mm}^{2}$ significantly increases in the SIV-infected DRGs. D: The box plot shows the absolute number of $\mathrm{CD} 8^{+}$cells per $\mathrm{mm}^{2}$ in mild, moderate, and severe DRGs. Elevated numbers of $\mathrm{CD}^{+} 8^{+}$macrophages are associated with severity of DRG pathology. Analysis of variance $(P<0.01)$ was performed, followed by post hoc $t$-tests. Data are given as means \pm SEM (C and D). $n=4$ (C, SIV ${ }^{-}$DRGs); $n=26$ (C, SIV ${ }^{+}$DRGs); $n=8$ (D, mild DRGs); $n=$ 12 (D, moderate DRGs); $n=6$ (D, severe DRGs). ${ }^{*} P<0.05,{ }^{* * *} P<0.001$.

pathology: mild, moderate, and severe (as described in Materials and Methods). There was a statistically significant difference in the amount of $\mathrm{CD}^{+} 8^{+}$macrophages $/ \mathrm{mm}^{2}$ of DRGs among the three groups $(P<0.01)$ (Figure 3D). There were more activated resident $\mathrm{CD}^{+} 8^{+}$macrophages in the DRGs with severe pathology compared with those with both mild $(P<0.05)$ and moderate $(P<0.05)$ pathology (Figure 3D).

To further phenotype the cells surrounding the DRG neurons, we examined the percentage of $\mathrm{CD} 163^{+}$M2-like macrophages (Table 2) and the absolute number of these cells in DRGs. The $\mathrm{CD}_{163^{+}}$macrophages made up an average of $5.8 \%$ (SEM, 2.1\%; range, $2.4 \%$ to $11.7 \%$ ) of all cells surrounding normal uninfected DRGs (Table 2). This percentage was increased to an average of $27.4 \%$ (SEM, $1.8 \%$; range, $4.5 \%$ to $45.5 \%$ ) in all DRGs from infected animals (Table 2). The absolute number of $\mathrm{CD}_{163}{ }^{+}$cells surrounding the DRG neurons was significantly increased in SIV-infected animals compared with uninfected controls $[P<0.01$ : mean, 262.3 (SEM, 106.7) versus 1200.0 (SEM, 105.1) cells $/ \mathrm{mm}^{2}$ ] (Figure 4, A-C). There was no significant difference in the amount of $\mathrm{CD} 163^{+}$cells in the DRGs with mild, moderate, or severe pathology (Figure 4D).

We have previously shown that absolute number of $\mathrm{CD}^{+}$ and $\mathrm{CD} 8^{+}$cells was not different between SIV-infected and uninfected DRGs. ${ }^{20} \mathrm{CD} 4$ immunohistochemistry is not reliable in rhesus paraffin-embedded tissue sections because of low antigenicity. To confirm the extent of T lymphocytes in 

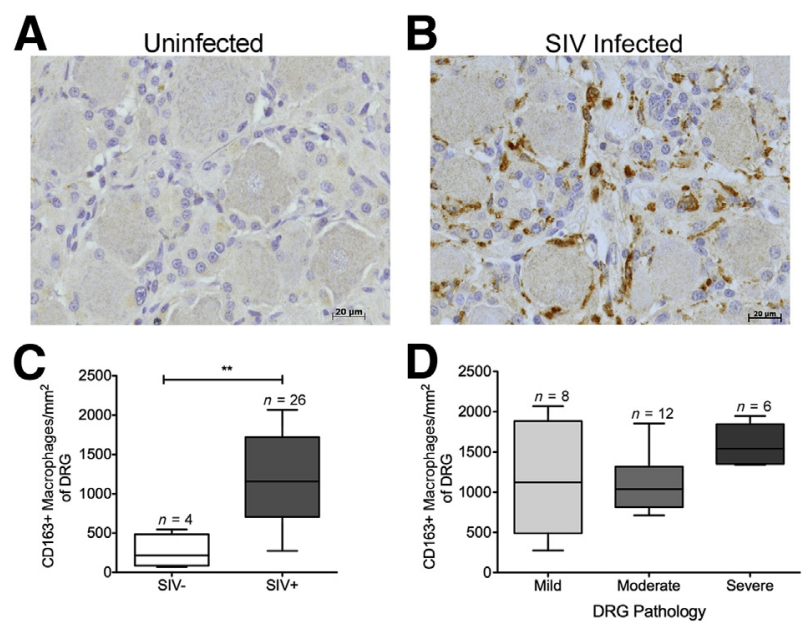

Figure 4 Elevated numbers of $\mathrm{CD} 163^{+}$macrophages are associated with SIV infection. A: Dorsal root ganglion (DRG) of uninfected animal A02 with scant CD163 immunoreactivity (brown). B: DRG of SIV-infected animal A05 with marked increase in CD163 immunoreactivity (brown). C: The box plot shows the absolute number of $\mathrm{CD}_{163}{ }^{+}$cells per $\mathrm{mm}^{2}$ in $\mathrm{SIV}^{-}$and $\mathrm{SIV}^{+}$ DRGs. The absolute number of $\mathrm{CD}_{163^{+}}$cells per $\mathrm{mm}^{2}$ significantly increases in the SIV-infected group. D: The box plot shows the absolute number of $\mathrm{CD}_{163}{ }^{+}$cells per $\mathrm{mm}^{2}$ in mild, moderate, and severe DRGs. Elevated numbers of $\mathrm{CD} 163^{+}$macrophages were not associated with severity of DRG pathology. Data are given as means \pm SEM (C and D). $n=4$ (C, SIV DRGs); $n=26$ (C, SIV ${ }^{+}$DRGs); $n=8$ (D, mild DRGs); $n=12$ (D, moderate DRGs); $n=6$ (D, severe DRGs). ${ }^{* \star} P<0.01$.

DRG tissues, we used the pan T-cell marker CD3 to quantitate percentage and absolute number of T cells in the DRG. The mean absolute number of $\mathrm{CD}^{+}{ }^{+} \mathrm{T}$ lymphocytes in DRG tissue was not significantly different between uninfected and SIV-infected animals [mean, 232.8 (SEM, 54.3) versus 249.5 (SEM, 43.3) cells $/ \mathrm{mm}^{2}$ ] (Table 2).

\section{Immune Cell Traffic in DRGs}

To identify monocytes that recently emigrated from bone marrow, we used BrdU labeling in SIV-infected, $\mathrm{CD}^{+}$ T-lymphocyte-depleted macaques. Newly migrated monocytes/macrophages were identified within the DRG using both anti-BrdU and anti-MAC387 antibodies. BrdU ${ }^{+}$cells in DRGs were quantified in uninfected compared with SIVinfected macaques (Figure 5, A-C). There were $<1 \%$ of $\mathrm{BrdU}^{+}$cells in the DRGs of uninfected animals, representing a basal level of cell turnover in the DRGs (Table 2). The absolute number of $\mathrm{BrdU}^{+}$cells trafficking to the DRG tissue trended toward an increase with SIV infection [mean, 40.0 (SEM, 0.5) versus 148.5 (SEM, 26.6) cells $/ \mathrm{mm}^{2}$ ] (Figure 5C). When DRGs were divided by severity of pathology, $\mathrm{BrdU}^{+}$cells were significantly different among groups (analysis of variance $P<0.01$ ) (Figure 5D). $\mathrm{BrdU}^{+}$ cells were significantly elevated in the severe group compared with the mild $(P<0.05)$ and moderate $(P<0.05)$ groups (Figure 5D). Thus, trafficking of $\mathrm{BrdU}^{+}$cells from the bone marrow to the DRG correlates with severity of DRG pathology. We also found that the average number of $\mathrm{BrdU}^{+}$ cells in the DRG positively and significantly correlated with the percentage loss of IENFD at necropsy $(P<0.05$, $r=0.64$ ) (Figure 5E). The number of $\mathrm{CD} 68^{+}$and $\mathrm{CD} 163^{+}$ macrophages, $\mathrm{MAC}_{387^{+}}$recently recruited cells, and $\mathrm{CD} 3^{+}$ $\mathrm{T}$ cells in the DRG did not correlate with IENFD loss (data not shown). These data suggest an association between monocyte recruitment from the bone marrow to DRG histopathology and IENFD loss.

MAC $387^{+}$cells are early inflammatory cells that represent recent recruits to tissues on inflammation and are considered to have an M1-like phenotype..$^{25,38,39}$ We found few MAC $387^{+}$cells in uninflamed tissues, and in the uninfected DRGs, they accounted for an average of $1.5 \%$ (SEM, $0.6 \%$; range, $0.7 \%$ to $3.1 \%$ ) of cells surrounding DRG neurons (Table 2). The percentage of MAC $387^{+}$cells surrounding the DRG neurons during SIV was increased to an average of
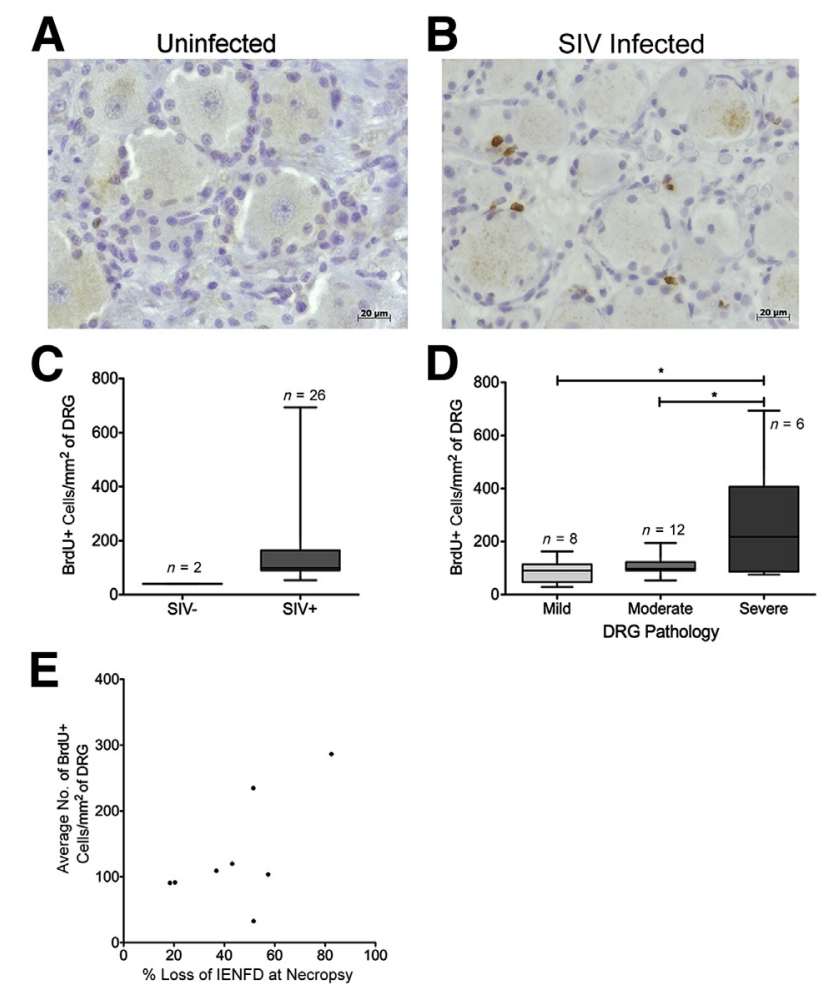

Figure 5 Cell traffic from the bone marrow to the dorsal root ganglion (DRG) measured by increased 5-bromo-2-deoxyuridine $\left(\mathrm{BrdU}^{+}\right)$cells with SIV infection. Animals were serially injected with BrdU to label recently divided monocytes in the bone marrow and then traffic to DRG. A: DRG of uninfected animal A02 with scant BrdU immunoreactivity (brown). B: DRG of SIV-infected animal A06 with marked increase in BrdU immunoreactivity (brown). C: The box plot shows the absolute number of $\mathrm{BrdU}^{+}$cells per $\mathrm{mm}^{2}$ in $\mathrm{SIV}^{-}$and $\mathrm{SIV}^{+}$DRGs. The absolute number of $\mathrm{BrdU}^{+}$cells per $\mathrm{mm}^{2}$ of DRG tissue was calculated. D: The box plot shows the absolute number of $\mathrm{BrdU}^{+}$ cells per $\mathrm{mm}^{2}$ in mild, moderate, and severe DRGs. Higher numbers of $\mathrm{BrdU}^{+}$cells correlate with the severity of DRG pathology. Analysis of variance $(P<0.01)$ was performed, followed by post hoc $t$-tests. E: The average number of $\mathrm{BrdU}^{+}$cells in the DRGs per animal was calculated. Increased numbers of $\mathrm{BrdU}^{+}$cells in the DRG correlate with percentage loss of intraepidermal nerve fiber density (IENFD) at necropsy. Spearman correlation was used. Data are given as means \pm SEM (C and D). $n=4$ (C, $\mathrm{SIV}^{-}$DRGs); $n=26$ (C, SIV ${ }^{+}$DRGs); $n=8$ (D, mild DRGs); $n=12$ (D, moderate DRGs); $n=6$ (D, severe DRGs). ${ }^{\star} P<0.05(r=0.064)$. 

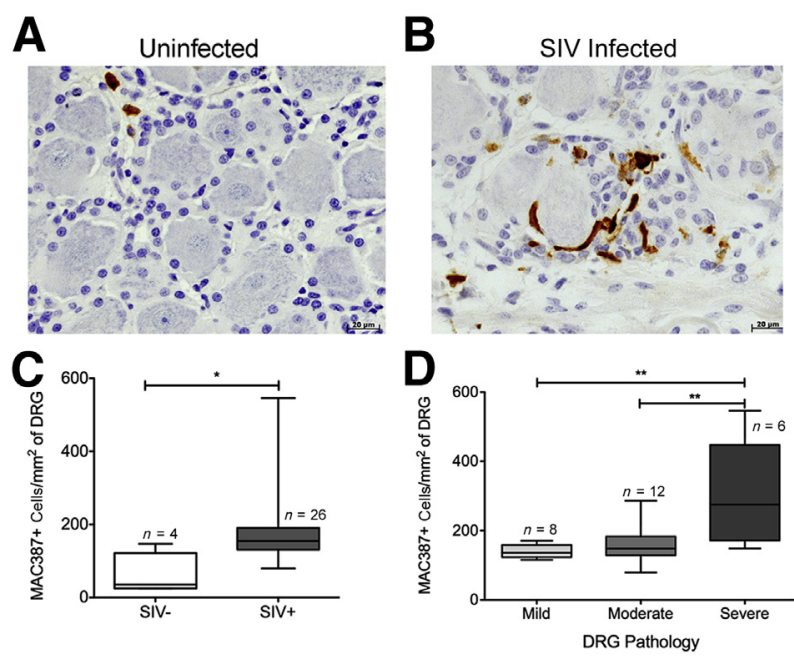

Figure 6 Elevated numbers of $\mathrm{MAC}_{387^{+}}$macrophages are associated with SIV infection and severity of dorsal root ganglion (DRG) pathology. A: DRG of uninfected animal A01 with scant MAC387 immunoreactivity (brown). B: DRG of SIV-infected animal A05 with marked increase in MAC387 immunoreactivity (brown). C: The box plot shows the absolute number of ${\mathrm{MAC} 387^{+}}^{+}$cells per $\mathrm{mm}^{2}$ in $\mathrm{SIV}^{-}$and $\mathrm{SIV}^{+}$DRGs. The absolute number of ${\mathrm{MAC} 387^{+}}^{+}$cells per $\mathrm{mm}^{2}$ significantly increases in the SIVinfected group. D: The box plot shows the absolute number of $\mathrm{MAC}_{3} 87^{+}$ cells per $\mathrm{mm}^{2}$ in mild, moderate, and severe DRGs. Elevated number of $\mathrm{MAC}_{38} 7^{+}$macrophages is associated with severity of DRG pathology. Analysis of variance $(P<0.01)$ was performed, followed by post hoc $t$-tests. Data are given as means \pm SEM (C and D). $n=4$ (C, SIV ${ }^{-}$DRGs); $n=26\left(\right.$ C, SIV ${ }^{+}$DRGs); $n=8$ (D, mild DRGs); $n=12$ (D, moderate DRGs); $n=6$ (D, severe DRGs). ${ }^{*} P<0.05,{ }^{*} P<0.01$.

$4.3 \%$ (SEM, $0.5 \%$ ). The absolute number of $\mathrm{MAC} 37^{+}$cells in the DRG tissue significantly increased in SIV-infected animals compared with uninfected controls $[P<0.05$ : mean, 60.4 (SEM, 29.1) versus 187.7 (SEM, 20.4) cells/ $\mathrm{mm}^{2}$ ] (Figure 6, A-C). When animals were separated by severity of DRG pathology (mild, moderate, and severe), the absolute numbers of MAC $387^{+}$cells were different among groups (analysis of variance $P<0.01$ ) (Figure 5D). MAC $387^{+}$cells were most abundant in the severe group compared with the mild $(P<0.01)$ and moderate $(P<0.01)$ groups (Figure 6D). Thus, the accumulation of MAC $387^{+}$ cells correlated with severity of DRG pathology.
To further characterize the $\mathrm{BrdU}^{+}$cells that have recently emigrated to the tissue, we performed doubleimmunofluorescence staining on DRG tissues for BrdU and MAC387 and BrdU and CD68. We found that an average of $78.1 \%$ (SEM, 3.5\%; range, $51.4 \%$ to $98.9 \%$ ) of total $\mathrm{BrdU}^{+}$cells were also $\mathrm{MAC} 387^{+}$, whereas only an average of $6.9 \%$ (SEM, $1.1 \%$; range, $3.4 \%$ to $12.2 \%$ ) of all $\mathrm{BrdU}^{+}$cells were also CD68 ${ }^{+}$(Table 3), which corroborates with our previously published data examining cell traffic to the brain, where we demonstrated that $90 \%$ of all $\mathrm{BrdU}^{+}$ cells in SIV encephalitic lesions were also MAC $387^{+} .21,25$ These data demonstrated that most of the $\mathrm{BrdU}^{+}$cells are also MAC $387^{+}$, and these cells were the main cell population trafficking to the DRG during SIV infection.

\section{Discussion}

HIV-induced DSP continues to negatively affect patient quality of life. Treatment for HIV-DSP currently focuses on treating the symptomatic pain because the underlying cause is poorly understood. ${ }^{2}$ Thus, there exists a need to understand the pathophysiological mechanisms of HIV-DSP. Herein, we characterized the immune response in the DRGs and correlated it with histopathology and IENFD loss in the peripheral nerves. The DRG has long been implicated in pathogenesis of HIV-DSP, but the mechanisms have not yet been fully characterized. ${ }^{5}$ Previous research suggested that macrophages may traffic to the DRG and inflict damage during HIV and SIV infection, ${ }^{17,20,24}$ but this has not been investigated systematically within an appropriate animal model.

This study was the first to study cell trafficking from the bone marrow to the DRG during SIV infection. Dividing cells were labeled using i.v. BrdU pulse. ${ }^{21} \mathrm{BrdU}$ is a thymidine analogue that incorporates into all newly synthesized DNA. Monocytes undergo their last cell division in the bone marrow; therefore, BrdU labels while they are in the bone marrow. ${ }^{40}$ We found an increased number of $\mathrm{BrdU}^{+}$macrophages in the DRGs with SIV infection. The amount of $\mathrm{BrdU}^{+}$cells increased with more severe DRG histopathology, suggesting a potential role in DRG pathology.

Table 3 Most BrdU ${ }^{+}$Cells Surrounding the DRG Neurons Are MAC387 ${ }^{+}$

\begin{tabular}{|c|c|c|c|c|c|c|}
\hline Type of $\mathrm{BrdU}^{+}$cells & A05 & A10 & A11 & A12 & A14 & $\begin{array}{l}\text { Weighted } \\
\text { average* }^{*}\end{array}$ \\
\hline $\mathrm{BrdU}^{+}{\mathrm{Mac} 387^{+}}$cells vs all BrdU ${ }^{+}$cells $^{\dagger}$ & $51.4 \pm 10.8$ & $91.1 \pm 3.9$ & $98.9 \pm 1.1$ & $87.3 \pm 8.9$ & $75.7 \pm 5.7$ & $78.1 \pm 3.5$ \\
\hline $\mathrm{BrdU}^{+} \mathrm{CD} 8^{+}$cells vs all $\mathrm{BrdU}^{+}$cells ${ }^{\ddagger}$ & $5.4 \pm 3.1$ & $12.2 \pm 2.8$ & $3.4 \pm 2.0$ & $5.9 \pm 1.2$ & $6.2 \pm 2.4$ & $6.9 \pm 1.1$ \\
\hline $\mathrm{BrdU}^{+} \mathrm{Mac} 387^{+}$cells vs all Mac387 ${ }^{+}$cells $^{\S}$ & $35.2 \pm 8.7$ & $75.7 \pm 3.7$ & $90.6 \pm 2.6$ & $96.0 \pm 1.7$ & $82.1 \pm 2.9$ & $74.5 \pm 2.2$ \\
\hline 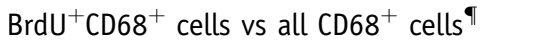 & $2.1 \pm 1.4$ & $2.4 \pm 0.8$ & $1.9 \pm 0.9$ & $1.4 \pm 0.3$ & $2.4 \pm 1.3$ & $2.1 \pm 0.5$ \\
\hline
\end{tabular}

\footnotetext{
*The averages shown are the weighted averages \pm SEM (pooled variance).

${ }^{\dagger}$ Means \pm SEM of the percentage of BrdU $^{+}$cells expressing Mac387 surrounding DRG neurons were calculated as follows: (number of BrdU ${ }^{+}$Mac387 $^{+}$cells/ total number of $\mathrm{BrdU}^{+}$cells) $\times 100$.

${ }^{\ddagger}$ Means \pm SEM of the percentage of $\mathrm{BrdU}^{+}$cells expressing $\mathrm{CD} 68$ were calculated as follows: (number of $\mathrm{BrdU}^{+} \mathrm{CD}^{+} 8^{+}$cells/total number of $\mathrm{BrdU}{ }^{+}$cells) $\times 100$.

${ }^{\S}$ Means \pm SEM of the percentage of Mac $387^{+}$cells expressing BrdU were calculated as follows: (number of BrdU ${ }^{+} \mathrm{Mac} 387^{+}$cells $/$total number of Mac387 ${ }^{+}$cells) $\times 100$.

${ }^{\top}$ Means \pm SEM of the percentage of $\mathrm{CD} 8^{+}$cells expressing BrdU were calculated as follows: (number of $\mathrm{BrdU}^{+} \mathrm{CD} 8^{+}$cells/total number of CD68 ${ }^{+}$cells) $\times 100$.

BrdU, 5-bromo-2-deoxyuridine; DRG, dorsal root ganglion.
} 
Our previous data demonstrated that $90 \%$ of $\mathrm{BrdU}^{+}$macrophages in the SIV encephalitic lesions were also MAC $387^{+}$ (a marker of recently recruited monocytes, M1-type macrophage), but few were $\mathrm{CD} 68^{+}$or $\mathrm{CD} 163^{+} .{ }^{25}$ Herein, we have demonstrated that most $\left(78.1 \%\right.$ ) of the $\mathrm{BrdU}^{+}$cells in DRGs were also MAC $387^{+}$and few (6.9\%) were $\mathrm{CD} 68^{+}$. Although there have been recent articles suggesting that macrophages undergo division in situ, ${ }^{41,42}$ we believe that these $\mathrm{BrdU}^{+}$ MAC $387^{+}$cells represent cells coming from the bone marrow, supported by the fact that BrdU is incorporated in monocytes in the bone marrow and that blood monocytes are MAC $387^{+}$ cells. In addition, MAC387 is a marker of monocytes that have recently infiltrated tissues and is perhaps the earliest marker expressed on such cells as they enter tissues. ${ }^{25}$ We found significantly increased numbers of MAC $387^{+}$macrophages in DRGs of SIV-infected animals compared with uninfected controls and, as expected, increased numbers of MAC $387^{+}$ cells also correlated with severity of DRG pathology. These data together suggest that newly recruited $\mathrm{BrdU}^{+} \mathrm{MAC} 387^{+}$ monocytes may play significant roles in severity of DRG pathogenesis during SIV infection. Our findings regarding cell traffic and the correlation to DRG pathology are consistent with previously published data that demonstrated a correlation between monocyte traffic and severity of SIV encephalitic brain lesions in the same model system. ${ }^{21}$

Previous studies of SIV-PN examined $\mathrm{CD}^{+} 8^{+}$or Iba- 1 macrophages in the DRG. ${ }^{17,18,20}$ Herein, CD68 was used as a marker for resident macrophages, and $\mathrm{CD} 163^{+}$cells represented M2-like perivascular macrophages. CD163 is a scavenger receptor expressed on activated mononuclear cells and is shed in its soluble form. ${ }^{43-45}$ Elevated soluble CD163 in plasma has been shown to be a biomarker of SIV and HIV infection and correlates with severity of neurological disease associated with HIV. ${ }^{21,44,46,47}$ These two markers are not expressed on exclusive cell populations. Most of the CD163 ${ }^{+}$ cells coexpress CD68 (data not shown). ${ }^{25}$ Both absolute numbers of $\mathrm{CD} 68^{+}$and $\mathrm{CD} 163^{+}$macrophages increased with SIV infection. Interestingly, only greater numbers of $\mathrm{CD}^{+} 8^{+}$, but not $\mathrm{CD}_{163}{ }^{+}$, macrophages correlated with severity of DRG pathology. It is possible that $\mathrm{CD} 163^{+}$ macrophages may be exerting a protective M2-like effect.

Macrophages are often classified as being either M1 or M2 polarized. However, M1 and M2 classifications are not rigid in that macrophages can switch phenotypes. HIV-1 proteins cause a phenotypic switch from M2 to M1 by preferentially activating M2 macrophages. ${ }^{48} \mathrm{CD} 163^{+}$cells are typically considered to be M2-polarized macrophages that are associated with tissue repair, tumor progression, and production of anti-inflammatory cytokines. ${ }^{49,50}$ In contrast, MAC $387^{+}$macrophages are thought to be M1 polarized, which produce proinflammatory cytokines and contribute to host protection from pathogens. ${ }^{49,50}$

We have previously shown that the absolute number of $\mathrm{CD}^{+}$ and $\mathrm{CD}^{+} \mathrm{T}$ lymphocytes was not different between SIVinfected and uninfected DRGs and have confirmed those data herein. ${ }^{20}$ CD4 immunohistochemistry was not performed, because it is not reliable in rhesus paraffin tissue sections because of low antigenicity. This suggests that macrophages, but not $\mathrm{T}$ cells, are either inflicting or exacerbating damage in the DRG.

Skin biopsy specimens are a valuable tool for clinical diagnosis of small-fiber neuropathies and have largely replaced sural nerve biopsy specimens for assessment of unmyelinated nerve fibers in conditions such as diabetic neuropathy and HIV-associated sensory neuropathy. A recent report ${ }^{6}$ indicates that rhesus macaques (inoculated with both the neurovirulent molecular SIV clone SIV/17E-Fr and the immunosuppressive strain SIV/DeltaB670) do not develop a significant decline in IENFDs. ${ }^{6}$ In contrast, herein, we show that SIVmac251-infected, CD8-depleted rhesus macaques show a significant decrease in IENFDs and that this decrease occurs early after infection. These differences may be due to the different viral swarms used in the models. The early loss of IENFD demonstrates that the animals developed signs of SIV-PN, early in infection, before AIDS-induced diarrhea could have caused a nutritional deficiency, resulting in metabolic neuropathy before sacrifice. Loss of IENF sensory fibers and pathology of the sensory nerve cell bodies that reside in the DRG are hallmarks of HIV/SIV pathogenesis. We do not see robust evidence of axonal degeneration along the course of the nerve, but there is subtle damage to the IENF in the skin. This may indicate concurrent damage to the IENF and the DRG, possibly by different mechanisms. Alternatively, enough time may not have passed to develop prominent lesions within the course of the nerve.

The continued high prevalence of DSP among HIVinfected patients calls for more research to understand the mechanisms of pathogenesis. Epidemiological data suggest that even with antiretroviral therapy, there is still a high prevalence of DSP, suggesting viral load does not solely control pathogenesis. ${ }^{1}$ In addition, studies should examine the effect of controlling viral load with antiretroviral therapy in the SIV model and its effect on immune cell traffic and activation. Additional areas of research should investigate anti-inflammatory drugs that could stop traffic to DRGs and potentially alleviate pathology.

\section{Acknowledgments}

We thank the veterinary staff at the New England Primate Research Center and Tulane National Primate Research Center for animal care, the pathology residents and staff for assisting with necropsies and tissue collection, and Dr. Ronald Desrosiers (University of Miami, Coral Gables, FL) for providing the SIVmac251.

\section{References}

1. Ellis RJ, Rosario D, Clifford DB, McArthur JC, Simpson D, Alexander T, Gelman BB, Vaida F, Collier A, Marra CM, Ances B, Atkinson JH, Dworkin RH, Morgello S, Grant I: Continued high prevalence and adverse clinical impact of human immunodeficiency virus-associated sensory neuropathy in the era of combination 
antiretroviral therapy: the CHARTER Study. Arch Neurol 2010, 67: $552-558$

2. Nicholas PK, Mauceri L, Slate Ciampa A, Corless IB, Raymond N, Barry DJ, Viamonte Ros A: Distal sensory polyneuropathy in the context of HIV/AIDS. J Assoc Nurses AIDS Care 2007, 18:32-40

3. Verma S, Estanislao L, Simpson D: HIV-associated neuropathic pain: epidemiology, pathophysiology and management. CNS Drugs 2005, 19:325-334

4. Ellis RJ, Marquie-Beck J, Delaney P, Alexander T, Clifford DB, McArthur JC, Simpson DM, Ake C, Collier AC, Gelman BB, McCutchan JA, Morgello S, Grant I: Human immunodeficiency virus protease inhibitors and risk for peripheral neuropathy. Ann Neurol 2008, 64:566-572

5. Pardo CA, McArthur JC, Griffin JW: HIV neuropathy: insights in the pathology of HIV peripheral nerve disease. J Peripher Nerv Syst 2001, 6:21-27

6. Mangus LM, Dorsey JL, Laast VA, Ringkamp M, Ebenezer GJ, Hauer P, Mankowski JL: Unraveling the pathogenesis of HIV peripheral neuropathy: insights from a simian immunodeficiency virus macaque model. ILAR J 2014, 54:296-303

7. Mellion ML, Silbermann E, Gilchrist JM, Machan JT, Leggio L, de la Monte S: Small-fiber degeneration in alcohol-related peripheral neuropathy. Alcohol Clin Exp Res 2014, 38:1965-1972

8. Kalita J, Chandra S, Bhoi SK, Agarwal R, Misra UK, Shankar SK, Mahadevan A: Clinical, nerve conduction and nerve biopsy study in vitamin B12 deficiency neurological syndrome with a short-term follow-up. Nutr Neurosci 2014, 17:156-163

9. England JD, Gronseth GS, Franklin G, Carter GT, Kinsella LJ, Cohen JA, Asbury AK, Szigeti K, Lupski JR, Latov N, Lewis RA, Low PA, Fisher MA, Herrmann DN, Howard JF Jr, Lauria G, Miller RG, Polydefkis M, Sumner AJ; American Academy of Neurology: Practice Parameter: evaluation of distal symmetric polyneuropathy: role of autonomic testing, nerve biopsy, and skin biopsy (an evidence-based review): report of the American Academy of Neurology, American Association of Neuromuscular and Electrodiagnostic Medicine, and American Academy of Physical Medicine and Rehabilitation. Neurology 2009, 72:177-184

10. Burdo TH, Miller AD: Animal models of HIV peripheral neuropathy. Future Virol 2014, 9:465-474

11. Keswani SC, Jack C, Zhou C, Hoke A: Establishment of a rodent model of HIV-associated sensory neuropathy. J Neurosci 2006, 26 10299-10304

12. Cao L, Butler MB, Tan L, Draleau KS, Koh WY: Murine immunodeficiency virus-induced peripheral neuropathy and the associated cytokine responses. J Immunol 2012, 189:3724-3733

13. Wallace VC, Blackbeard J, Pheby T, Segerdahl AR, Davies M, Hasnie F, Hall S, McMahon SB, Rice AS: Pharmacological, behavioural and mechanistic analysis of HIV-1 gp120 induced painful neuropathy. Pain 2007, 133:47-63

14. Shimojima M, Miyazawa T, Ikeda Y, McMonagle EL, Haining H, Akashi H, Takeuchi Y, Hosie MJ, Willett BJ: Use of CD134 as a primary receptor by the feline immunodeficiency virus. Science 2004 , 303:1192-1195

15. Kennedy JM, Hoke A, Zhu Y, Johnston JB, van Marle G, Silva C, Zochodne DW, Power C: Peripheral neuropathy in lentivirus infection: evidence of inflammation and axonal injury. AIDS 2004, 18:1241-1250

16. Lackner AA, Dandekar S, Gardner MB: Neurobiology of simian and feline immunodeficiency virus infections. Brain Pathol 1991, 1:201-212

17. Laast VA, Shim B, Johanek LM, Dorsey JL, Hauer PE, Tarwater PM, Adams RJ, Pardo CA, McArthur JC, Ringkamp M, Mankowski JL: Macrophage-mediated dorsal root ganglion damage precedes altered nerve conduction in SIV-infected macaques. Am J Pathol 2011, 179: 2337-2345

18. Laast VA, Pardo CA, Tarwater PM, Queen SE, Reinhart TA, Ghosh M, Adams RJ, Zink MC, Mankowski JL: Pathogenesis of simian immunodeficiency virus-induced alterations in macaque trigeminal ganglia. J Neuropathol Exp Neurol 2007, 66:26-34
19. Dorsey JL, Mangus LM, Oakley JD, Beck SE, Kelly KM, Queen SE, Metcalf Pate KA, Adams RJ, Marfurt CF, Mankowski JL: Loss of corneal sensory nerve fibers in SIV-infected macaques: an alternate approach to investigate HIV-induced PNS damage. Am J Pathol 2014, 184:1652-1659

20. Burdo TH, Orzechowski K, Knight HL, Miller AD, Williams K Dorsal root ganglia damage in SIV-infected rhesus macaques: an animal model of HIV-induced sensory neuropathy. Am J Pathol 2012, 180:1362-1369

21. Burdo TH, Soulas C, Orzechowski K, Button J, Krishnan A, Sugimoto C, Alvarez X, Kuroda MJ, Williams KC: Increased monocyte turnover from bone marrow correlates with severity of SIV encephalitis and CD163 levels in plasma. PLoS Pathogens 2010, 6: e1000842

22. Williams K, Burdo TH: Monocyte mobilization, activation markers, and unique macrophage populations in the brain: observations from SIV infected monkeys are informative with regard to pathogenic mechanisms of HIV infection in humans. J Neuroimmune Pharmacol 2012, 7:363-371

23. Rao VR, Ruiz AP, Prasad VR: Viral and cellular factors underlying neuropathogenesis in HIV associated neurocognitive disorders (HAND). AIDS Res Ther 2014, 11:13

24. Hahn K, Robinson B, Anderson C, Li W, Pardo CA, Morgello S, Simpson D, Nath A: Differential effects of HIV infected macrophages on dorsal root ganglia neurons and axons. Exp Neurol 2008, 210 $30-40$

25. Soulas C, Conerly C, Kim WK, Burdo TH, Alvarez X, Lackner AA, Williams KC: Recently infiltrating MAC387(+) monocytes/macrophages a third macrophage population involved in SIV and HIV encephalitic lesion formation. Am J Pathol 2011, 178:2121-2135

26. Lackner AA: Pathology of simian immunodeficiency virus induced disease. Curr Top Microbiol Immunol 1994, 188:35-64

27. Sasseville VG, Lackner AA: Neuropathogenesis of simian immunodeficiency virus infection in macaque monkeys. J Neurovirol 1997, 3:1-9

28. Schmitz JE, Kuroda MJ, Santra S, Sasseville VG, Simon MA, Lifton MA, Racz P, Tenner-Racz K, Dalesandro M, Scallon BJ, Ghrayeb J, Forman MA, Montefiori DC, Rieber EP, Letvin NL, Reimann KA: Control of viremia in simian immunodeficiency virus infection by CD8+ lymphocytes. Science 1999, 283:857-860

29. Westmoreland SV, Halpern E, Lackner AA: Simian immunodeficiency virus encephalitis in rhesus macaques is associated with rapid disease progression. J Neurovirol 1998, 4:260-268

30. Williams K, Westmoreland S, Greco J, Ratai E, Lentz M, Kim WK, Fuller RA, Kim JP, Autissier P, Sehgal PK, Schinazi RF, Bischofberger N, Piatak M, Lifson JD, Masliah E, Gonzalez RG: Magnetic resonance spectroscopy reveals that activated monocytes contribute to neuronal injury in SIV neuroAIDS. J Clin Invest 2005, 115:2534-2545

31. Williams KC, Hickey WF: Central nervous system damage, monocytes and macrophages, and neurological disorders in AIDS. Annu Rev Neurosci 2002, 25:537-562

32. Williams K, Schwartz A, Corey S, Orandle M, Kennedy W, Thompson B, Alvarez X, Brown C, Gartner S, Lackner A: Proliferating cellular nuclear antigen expression as a marker of perivascular macrophages in simian immunodeficiency virus encephalitis. Am J Pathol 2002, 161:575-585

33. Kim WK, Alvarez X, Fisher J, Bronfin B, Westmoreland S, McLaurin J, Williams K: CD163 identifies perivascular macrophages in normal and viral encephalitic brains and potential precursors to perivascular macrophages in blood. Am J Pathol 2006, 168:822-834

34. Fox CH, Cottler-Fox M: In situ hybridization for detection of HIV RNA. Curr Protoc Immunolo 2001 May, Chapter 12:Unit 12.8

35. Mangus LM, Dorsey JL, Laast VA, Hauer P, Queen SE, Adams RJ, McArthur JC, Mankowski J: Neuroinflammation and virus replication in the spinal cord of simian immunodeficiency virus-infected macaques. J Neuropathol Exp Neurol 2015, 74:38-47

36. Ebenezer GJ, Laast VA, Dearman B, Hauer P, Tarwater PM, Adams RJ, Zink MC, McArthur JC, Mankowski JL: Altered cutaneous 
nerve regeneration in a simian immunodeficiency virus/macaque intracutaneous axotomy model. J Comp Neurol 2009, 514:272-283

37. Provitera V, Nolano M, Caporaso G, Stancanelli A, Manganelli F, Iodice R, Selim MM, De Rosa A, Lanzillo B, Pellecchia MT, De Michele G, Santoro L: Postganglionic sudomotor denervation in patients with multiple system atrophy. Neurology 2014, 82:2223-2229

38. Esiri MM, Morris CS: Immunocytochemical study of macrophages and microglial cells and extracellular matrix components in human CNS disease, 2: non-neoplastic diseases. J Neurol Sci 1991, 101:59-72

39. Otani I, Mori K, Sata T, Terao K, Doi K, Akari H, Yoshikawa Y: Accumulation of MAC387+ macrophages in paracortical areas of lymph nodes in rhesus monkeys acutely infected with simian immunodeficiency virus. Microbes Infect 1999, 1:977-985

40. Hasegawa A, Liu H, Ling B, Borda JT, Alvarez X, Sugimoto C, Vinet-Oliphant H, Kim WK, Williams KC, Ribeiro RM, Lackner AA, Veazey RS, Kuroda MJ: The level of monocyte turnover predicts disease progression in the macaque model of AIDS. Blood 2009, 114: 2917-2925

41. Robbins CS, Hilgendorf I, Weber GF, Theurl I, Iwamoto Y, Figueiredo JL, Gorbatov R, Sukhova GK, Gerhardt LM, Smyth D, Zavitz CC, Shikatani EA, Parsons M, van Rooijen N, Lin HY, Husain M, Libby P, Nahrendorf M, Weissleder R, Swirski FK: Local proliferation dominates lesional macrophage accumulation in atherosclerosis. Nat Med 2013, 19:1166-1172

42. Amano SU, Cohen JL, Vangala P, Tencerova M, Nicoloro SM, Yawe JC, Shen Y, Czech MP, Aouadi M: Local proliferation of macrophages contributes to obesity-associated adipose tissue inflammation. Cell Metab 2014, 19:162-171
43. Weaver LK, Hintz-Goldstein KA, Pioli PA, Wardwell K, Qureshi N, Vogel SN, Guyre PM: Pivotal advance: activation of cell surface Toll-like receptors causes shedding of the hemoglobin scavenger receptor CD163. J Leukoc Biol 2006, 80:26-35

44. Burdo TH, Lentz MR, Autissier P, Krishnan A, Halpern E, Letendre S, Rosenberg ES, Ellis RJ, Williams KC: Soluble CD163 made by monocyte/macrophages is a novel marker of HIV activity in early and chronic infection prior to and after anti-retroviral therapy. J Infect Dis 2011, 204:154-163

45. Davis BH, Zarev PV: Human monocyte CD163 expression inversely correlates with soluble CD163 plasma levels. Cytometry B Clin Cytom 2005, 63:16-22

46. Burdo TH, Lo J, Abbara S, Wei J, DeLelys ME, Preffer F, Rosenberg ES, Williams KC, Grinspoon S: Soluble CD163, a novel marker of activated macrophages, is elevated and associated with noncalcified coronary plaque in HIV-infected patients. J Infect Dis 2011, 204:1227-1236

47. Burdo TH, Weiffenbach A, Woods SP, Letendre S, Ellis RJ, Williams KC: Elevated sCD163 in plasma but not cerebrospinal fluid is a marker of neurocognitive impairment in HIV infection. AIDS 2013, 27:1387-1395

48. Chihara T, Hashimoto M, Osman A, Hiyoshi-Yoshidomi Y, Suzu I, Chutiwitoonchai N, Hiyoshi M, Okada S, Suzu S: HIV-1 proteins preferentially activate anti-inflammatory M2-type macrophages. J Immunol 2012, 188:3620-3627

49. Davies LC, Jenkins SJ, Allen JE, Taylor PR: Tissue-resident macrophages. Nat Immunol 2013, 14:986-995

50. Liu YC, Zou XB, Chai YF, Yao YM: Macrophage polarization in inflammatory diseases. Int J Biol Sci 2014, 10:520-529 